The authors wish to thank the Medical Research Council for a grant from which the expenses of this work were defrayed, E. R. Squibb and Sons for a generous gift of oestrone, Professor R. J. Kellar and Dr Susanne Paterson of the Department of Obstetrics and Gynaecology and Dr A. Klopper of the Clinical Endocrinology Research Unit (M.R.C.) for providing facilities for the collection of urine, and Dr J. W. Minnis for carrying out the microanalyses.

\section{REFERENCES}

Allen, W. M. (1950). J. clin. Endocrin. 10, 71.

Barton, D. H. R. \& Klyne, W. (1948). Chem. \& Ind. p. 755.

Bauld, W. S. (1954). Biochem. J. 56, 426.

Bauld, W. S. (1955). Biochem. J. 59, 294.

Biel, J. H. (1951). J. Amer. chem. Soc. 73, 847.

Brown, J. B. (1952). J. Endocrin. 8, 196.

Cooley, G., Ellis, B., Hartley, F. \& Petrov, V. (1955). J. chem. Soc. p. 4373.

Dodgson, K. S. \& Spencer, B. (1953). Biochem. J. 55, 315.

Fishman, W. H. (1948). J. biol. Chem. 173, 449.
Fried, J., Thoma, R. W., Perlman, D., Herz, J. E. \& Borman, A. (1955). Recent Progr. Hormone Res. 11, 149.

Huffman, M. N. (1942). J. Amer. chem. Soc. 64, 2235.

Huffman, M. N. \& Grollman, A. (1947). Endocrinology, 41, 12.

Huffman, M. N. \& Lott, M. H. (1948). J. biol. Chem. 172, 325.

Huffman, M. N. \& Lott, M. H. (1955). J. biol. Chem. 215, 627.

Leeds, N. S., Fukushima, D. K. \& Gallagher, T. F. (1954). J. Amer. chem. Soc. 76, 2943.

Longwell, B. \& Wintersteiner, O. (1940). J. biol. Chem. 133, 219.

Mader, W. J. \& Buck, R. R. (1952). Analyt. Chem. 24, 666.

Marrian, G. F. \& Bauld, W. S. (1955). Biochem. J. 59, 136.

Migeon, C. J. (1953). J. clin. Endocrin. Metab. 13, 674.

Pincus, G. \& Pearlman, N. H. (1943). Vitam. \& Horm. 1, 334.

Watson, E. J. D. \& Marrian, G. F. (1955). Biochem. J. 61, xxiv.

Watson, E. J. D. \& Marrian, G. F. (1956). Biochem. J. 63, 64.

\title{
The Occurrence of $\boldsymbol{n}$-Heptadecanoic Acid (Margaric Acid) in Unhydrogenated Mutton Fat
}

\author{
By R. P. HANSEN, F. B. SHORLAND AND N. JUNE COOKE \\ Fats Research Laboratory, Department of Scientific and Industrial Research, Wellington, New Zealand
}

(Received 5 June 1956)

When margaric acid was formerly isolated from mutton fat (Hansen, Shorland \& Cooke, 1954) hydrogenation was employed in the method adopted. Accordingly it was not established whether this acid occurred as such in the natural fat, or whether it resulted (in part or in whole) from hydrogenation of either $\mathrm{a} \mathrm{C}_{17}$ unsaturated acid or of a cyclopropane ring (cf. Hofmann \& Lucas, 1950; Hofmann, Lucas \& Sax, 1952). As $\Delta^{9}$-heptadecenoic acid has been identified in lamb-caul fat (Shorland \& Jessop, 1955) its presence in mutton fat is expected, and this, on hydrogenation, could account for at least part of the margaric acid present. On the other hand, cyclopropane rings have not been shown to occur in natural glycerides, although, as reported by Hofmann et al. (1952), they are present in the lipids of certain species of Lactobaccilus, and on hydrogenation they yield a methyl-branched-chain acid and a normal odd-numbered fatty acid.

In the work now reported a sample of external carcass fat of sheep has been investigated by methods which did not include hydrogenation, and it has been found to contain appreciable quantities of margaric acid.

\section{EXPERIMENTAL}

A sample of external carcass fat of sheep (G/99; $31.2 \mathrm{~kg}$.) was steam-rendered, saponified, and converted into fatty acids. The fatty acids were steam-distilled (see McInnes, Hansen \& Jessop, 1956), and the steam-non-volatile acids $(21.58 \mathrm{~kg}$.) were converted into methyl esters $(20.47 \mathrm{~kg}$.) and distilled in vacuo in a fractionating column (approx. $180 \mathrm{~cm} . \times 12 \mathrm{~cm}$.) packed with $0.4-0.2 \mathrm{~mm}$. stainless-steel packing of the type described by Lecky \& Ewell (1940). Six fractions and a residue resulted, the fourth fraction (F4; 4285 g., saponification equiv. 288.6, iodine value $51 \cdot 1$, m.p. approx. $15 \cdot 0^{\circ}$ ) being relevant to this paper. Fraction F4 was refractionated in vacuo, a $490 \mathrm{~cm} . \times 3 \cdot 8 \mathrm{~cm}$. stainless-steel column packed with 3-4 mm. diameter single-turn glass helices being used. The first fraction distilled (F4, 1; 376 g., saponification equiv. 276.8, iodine value 18.8) was then refractionated in column $G$ (described by Shorland, Gerson \& Hansen, 1955), yielding 11 fractions $(\mathrm{F} 4,1,1-\mathrm{F} 4,1,11)$ and a residue $(\mathrm{F4}, 1, \mathrm{R} ; 37.40 \mathrm{~g}$., saponification equiv. 296.1, iodine value 58.8, m.p. 15.5$16 \cdot 0^{\circ}$. Fraction F4, 1, R (34.7 g.) was then refractionated in column $E$ (Shorland, 1952) into 13 fractions (F4, 1, R1$F 4,1, R 13)$ and a residue $(F 4,1, R R$; see Table 1$)$.

Fractions F4, 1, R1-F4, 1, R5 were combined, denoted $\mathrm{Xl}$, and as acids submitted to a series of low-temperature 
Table 1. Fractional distillation of methyl ester fraction F4, 1, $R(34 \cdot 7 \mathrm{~g}$.)

\begin{tabular}{|c|c|c|c|c|}
\hline Fraction & $\begin{array}{l}\text { Wt. } \\
\text { (g.) }\end{array}$ & M.p. of ester & $\begin{array}{c}\text { Saponification } \\
\text { equiv. }\end{array}$ & $\begin{array}{l}\text { Iodine value } \\
\text { (Wijs) }\end{array}$ \\
\hline $\mathrm{F4}, 1, \mathrm{R} 1$ & $1 \cdot 73$ & $22 \cdot 0-23 \cdot 1^{\circ}$ & $290 \cdot 5$ & $33 \cdot 0)$ \\
\hline F4, $1, \mathrm{R} 2$ & 1.97 & $23 \cdot 2-25 \cdot 0$ & 289.7 & $25 \cdot 4$ \\
\hline F4, 1, R3 & $1 \cdot 49$ & $22 \cdot 8-24 \cdot 8$ & $290 \cdot 7$ & 27.0 \\
\hline F4, 1, R4 & $0 \cdot 66$ & $20 \cdot 0-24 \cdot 8$ & $290 \cdot 3$ & $32 \cdot 7$ \\
\hline $\mathbf{F} 4,1, \mathrm{R} 5$ & $2 \cdot 93$ & $22 \cdot 3-23 \cdot 4$ & $291 \cdot 0$ & 31.9 \\
\hline $\mathrm{F4}, 1, \mathrm{R} 6$ & $4 \cdot 12$ & $15 \cdot 5-18 \cdot 0$ & $293 \cdot 6$ & $53.5 \times 4$ \\
\hline F4, 1, R7 & $3 \cdot 39$ & $-21 \cdot 0-16 \cdot 0$ & $294 \cdot 6$ & $62 \cdot 6$ \\
\hline F4, 1, R8 & 3.00 & $-19 \cdot 8-14.0$ & $295 \cdot 4$ & $68 \cdot 8$ \\
\hline F4, 1, R9 & $3 \cdot 25$ & $-17 \cdot 0-14 \cdot 3$ & $296 \cdot 4$ & $72 \cdot 6$ \\
\hline $\mathrm{F} 4, \mathbf{1}, \mathrm{R} 10$ & $3 \cdot 07$ & $-19 \cdot 0-10 \cdot 0$ & $297 \cdot 6$ & $77 \cdot 9$ \\
\hline $\mathrm{F} 4,1, \mathrm{R} 11$ & $2 \cdot 46$ & $-17 \cdot 0-15 \cdot 0$ & $298 \cdot 0$ & $76 \cdot 7$ \\
\hline $\mathrm{F} 4,1, \mathrm{R} 12$ & $2 \cdot 51$ & $-17 \cdot 0-19 \cdot 5$ & $298 \cdot 5$ & $75 \cdot 3$ \\
\hline $\mathrm{F} 4, \mathrm{l}, \mathrm{R} 13$ & $1 \cdot 80$ & $-17 \cdot 0-23 \cdot 5$ & $299 \cdot 1$ & $68 \cdot 5$ \\
\hline F4, 1, RR & $2 \cdot 07$ & - & $451 \cdot 7$ & - \\
\hline
\end{tabular}

Table 2. Low-temperature crystallization of fatty acid fraction $X 1$

Each fraction was crystallized at $-40^{\circ}$ from $40 \mathrm{vol}$. of the appropriate solvent.

\begin{tabular}{|c|c|c|c|c|c|c|c|c|}
\hline \multirow[b]{2}{*}{ Fraction } & \multirow[b]{2}{*}{$\begin{array}{l}\text { Wt. } \\
\text { (g.) }\end{array}$} & \multirow[b]{2}{*}{ Solvent } & \multicolumn{3}{|c|}{ Soluble } & \multicolumn{3}{|c|}{ Insoluble } \\
\hline & & & Fraction & $\begin{array}{l}\text { Wt. } \\
\text { (g.) }\end{array}$ & M.p. & Fraction & $\begin{array}{l}\text { Wt. } \\
\text { (g.) }\end{array}$ & M.p. \\
\hline $\begin{array}{l}\text { X1 } \\
\text { X1S } \\
\text { X1SS } \\
\text { X1S2S } \\
\text { X1S3S }\end{array}$ & $\begin{array}{l}7 \cdot 53 \\
4 \cdot 78 \\
4 \cdot 51 \\
4 \cdot 33 \\
4 \cdot 17\end{array}$ & $\begin{array}{l}\text { Acetone } \\
\text { Acetone } \\
\text { Ether } \\
\text { Ether } \\
\text { Acetone }\end{array}$ & $\begin{array}{l}\text { X1L } \\
\text { X1SL } \\
\text { X1S2L } \\
\text { X1S3L } \\
\text { X1S4L }\end{array}$ & $\begin{array}{l}2 \cdot 75 \\
0 \cdot 11 \\
0 \cdot 16 \\
0 \cdot 15 \\
0.02\end{array}$ & $\begin{array}{r}5 \cdot 0-6 \cdot 2^{\circ} \\
35 \cdot 0-36 \cdot 3 \\
57 \cdot 0-58 \cdot 0 \\
59 \cdot 2-59 \cdot 9 \\
51 \cdot 8-52 \cdot 0\end{array}$ & $\begin{array}{l}\text { X1S } \\
\text { X1SS } \\
\text { X1S2S } \\
\text { X1S3S } \\
\text { X1S4S }\end{array}$ & $\begin{array}{l}4 \cdot 78 \\
4 \cdot 51 \\
4 \cdot 33 \\
4 \cdot 17 \\
4 \cdot 16\end{array}$ & $\begin{array}{l}60 \cdot 8-61 \cdot 2^{\circ} \\
61 \cdot 2-61 \cdot 6 \\
61 \cdot 4-61 \cdot 8 \\
61 \cdot 8-62 \cdot 0 \\
61 \cdot 2-61 \cdot 7\end{array}$ \\
\hline
\end{tabular}

crystallizations (see Table 2), finally yielding fraction X1S4S (4.16 g.) with the following properties, which corresponded to those of margaric acid: m.p. 61.2-61.7 (reported m.p.'s: 61.3, Francis \& Piper, 1939; 60.3 ${ }^{\circ}$, Weitkamp, Smiljanic \& Rothman, 1947); when mixed with an equal quantity of pure margaric acid (m.p. 61·3-61.4 ${ }^{\circ}$ it gave a mixed m.p. of $61 \cdot 3-61 \cdot 6^{\circ}$; iodine value $0 \cdot 0 ; X$-ray long spacing $40 \cdot 4 \pm 0 \cdot 5 \AA$ [reported values for $n$-heptadecanoic acid: $40.45 \AA$ (Francis \& Piper, 1939); 40.05 (Slagle \& Ott, 1933); $40 \cdot 3 \AA$ (Stenhagen \& von Sydow, 1953)]; $n_{D}^{70} 1 \cdot 4328$ [reported value: $n_{\mathrm{D}}^{\mathbf{7 0}} \mathbf{1 \cdot 4 3 2 4}$ (Dorinson, McCorkle \& Ralston, 1942)]. (Found: $\mathrm{C}, 75 \cdot 7 ; \mathrm{H}, 12.4 \%$; saponification equiv. 270.6. Calc. for $\mathrm{C}_{17} \mathrm{H}_{34} \mathrm{O}_{2}: \mathrm{C}, 75 \cdot 5 ; \mathrm{H}, 12 \cdot 7 \%$; saponification equiv. 270.4.) Methyl ester: m.p. 29.8-30.3 ${ }^{\circ}$ [reported value: m.p. $29 \cdot 7^{\circ}$ (Francis \& Piper, 1939)]; $n_{D}^{40} 1 \cdot 4352$.

A further fraction X4S6S (1.18 g.) was separated by similar low-temperature crystallization from F4, 1, R6 (Table 1). Its properties were as follows: m.p. 61.2-61.5 , saponification equiv. $271 \cdot 3, X$-ray long spacing $39 \cdot 8 \pm 0 \cdot 5 \AA$.

As is characteristic of normal saturated odd-numbered acids, both fractions X1S4S and X4S6S readily shrank from the walls of their glass containers when allowed to cool from the melt. Melting points were determined in closed capillaries and are uncorrected. The combustion analysis was made by Dr A. D. Campbell, University of Otago, New Zealand. X-ray measurements were made with a Philips Geiger X-ray spectrometer, manganese-filtered iron $\mathbf{K} \alpha$ radiation being used. For the $\mathrm{X}$-ray determination the sample was prepared by evaporation from benzene.

\section{DISCUSSION}

The physical and chemical properties of fraction X1S4S establish it as the straight-chain $\mathrm{C}_{17}$ saturated acid, $n$-heptadecanoic acid. The occurrence of normal saturated odd-numbered fatty acids in natural fats was first established by Jantzen \& Witgert (1939), who identified minute traces of $n$ nonanoic, $n$-undecanoic and $n$-tridecanoic acids in coconut oil. Nobori (1942) later confirmed the presence of $n$-undecanoic and $n$-tridecanoic acids in coconut oil. Margaric acid, however, was first obtained from a natural source by Weitkamp et al. (1947), who isolated it, together with other normal saturated and unsaturated odd-numbered fatty acids, from the free-fatty acid fraction of humanhair fat. Subsequently it was found in hydrogenated mutton fat and ox fat (Hansen et al. 1954, 1957) and in shark-liver oil (Morice \& Shorland, 1955). In the latter investigation, as in the one now reported, hydrogenation was not employed.

\section{SUMMARY}

$n$-Heptadecanoic acid (margaric acid) has been isolated from unhydrogenated mutton fat. 
We are indebted to Dr G. G. Claridge of the Soil Bureau, Department of Scientific and Industrial Research, Wellington, New Zealand, for the X-ray measurements reported in this paper.

\section{REFERENCES}

Dorinson, A., McCorkle, M. R. \& Ralston, A. W. (1942). J. Amer. chem. Soc. 64, 2739.

Francis, F. \& Piper, S. H. (1939). J. Amer. chem. Soc. 61, 577.

Hansen, R. P., Shorland, F. B. \& Cooke, N. J. (1954). Biochem. J. 58, 513.

Hansen, R. P., Shorland, F. B. \& Cooke, N. J. (1957). J. Sci. Fd Agric. (in the Press).

Hofmann, K. \& Lucas, R. A. (1950). J. Amer. chem. Soc. 72, 4328.

Hofmann, K., Lucas, R. A. \& Sax, S. M. (1952). J. biol. Chem. 195, 473.
Jantzen, E. \& Witgert, H. (1939). Fette u. Seif. 46, 563.

Lecky, H. S. \& Ewell, R. H. (1940). Industr. Engng Chem. (Anal.), 12, 544.

McInnes, A. G., Hansen, R. P. \& Jessop, A. S. (1956). Biochem. J. 63, 702.

Morice, I. M. \& Shorland, F. B. (1955). Biochem. J. 61, 453.

Nobori, H. (1942). J. Soc. chem. Ind., Japan, 45, 48 B.

Shorland, F. B. (1952). J. appl. Chem. 2, 438.

Shorland, F. B., Gerson, T. \& Hansen, R. P. (1955). Biochem. J. 59, 350.

Shorland, F. B. \& Jessop, A. S. (1955). Nature, Lond., 176, 737.

Slagle, F. B. \& Ott, E. (1933). J. Amer. chem. Soc. 55, 4396.

Stenhagen, E. \& von Sydow, E. (1953). Ark. Kemi Min. Geol. A, 26, no. 19.

Weitkamp, A. W., Smiljanic, A. M. \& Rothman, S. (1947). J. Amer. chem. Soc. 69, 1936.

\title{
Glucose Metabolism in Candida Species
}

\author{
By K. RAMACHANDRAN* AND T. K. WALKER \\ College of Technology, University of Manchester
}

(Received 12 July 1956)

The information available concerning chemical processes in Candida species is somewhat limited. In particular, their behaviour towards glucose does not seem to have been studied in detail. Recently, Lodder \& Kreger-van Rij (1952) have brought all species of the genus of asporogenous yeast-like fungi known as Mycoderma, into the genus Candida under the name Candida mycoderma (Reess) Lodder \& Kreger-van Rij. For the purposes of our inquiry we obtained from the Delft Collection 12 authentic cultures of Candida species, including representatives of the former genus Mycoderma. In addition, seven strains were selected from a number of cultures of C. mycoderma, isolated at Manchester and described by Walker \& Wiles (1952).

The behaviour of these 19 organisms in defined media which contained glucose as sole source of carbon was then studied.

\section{EXPERIMENTAL AND RESULTS}

Particulars of the strains. Cultures received from the Centralbureau voor Schimmelcultures, Delft, Holland were labelled: (1) Candida lipolytica (Harrison) Diddens \& Lodder; (2) Pseudomonilia albomarginata. Geiger; (3) Candida monosa (Kluyver) Diddens \& Lodder; (4) Candida krusei (A. Cast.) Berkhout (=Mycoderma bordetii Kuff); (5) C. krusei (A. Cast.) Berkhout (= Mycoderma chevalieri

* Present address: Central Laboratories for Scientific and Industrial Research, P.O. Tamai Osmania, Hyderabad 7, India.
Guill); (6) and (7) other strains of C. krusei; (8) Candida rugosa (Anderson) Diddens \& Lodder; (9) Mycoderma lafarii Janke; (10) Mycoderma tannica Asai; (11) Mycoderma valida Leberle; (12) Mycoderma cerevisiae Desmazières strain gallica (Leberle). The seven strains of Candida mycoderma which had been isolated at Manchester were designated each by the letter $\mathrm{L}$ followed by a number. Stock cultures were maintained on malt-wort agar containing $1 \%$ $(v / v)$ of yeast autolysate. In view of the new classification of yeasts by Lodder \& Kreger-van Rij (1952) cultures 3-7 are possibly related and cultures 9-12 also are possibly related.

Media and procedure. All the cultures, with the exception of two of the strains of $C$. mycoderma, developed strongly and formed acid in medium $A$, which consisted of: $2.5 \mathrm{~g}$. of $\left(\mathrm{NH}_{4}\right)_{2} \mathrm{HPO}_{4}, 2 \mathrm{~g}$. of $\mathrm{KH}_{2} \mathrm{PO}_{4}, 1 \mathrm{~g}$. of $\mathrm{MgSO}_{4}, 7 \mathrm{H}_{2} \mathrm{O}, 0.01 \mathrm{~g}$. of $\mathrm{FeSO}_{4}, 7 \mathrm{H}_{2} \mathrm{O}, 100 \mathrm{~g}$. of glucose, water to $1 \mathrm{l}$.; the $\mathrm{pH}$ value was adjusted to $6 \cdot 0$. The two remaining strains showed only weak growth in this medium but developed well in medium $B$, which contained: $3 \mathrm{~g}$. of $\left(\mathrm{NH}_{4}\right)_{2} \mathrm{SO}_{4}, 3 \mathrm{~g}$. of $\mathrm{KH}_{2} \mathrm{PO}_{4}, 2 \mathrm{~g}$. of $\mathrm{MgSO}_{4}, 7 \mathrm{H}_{2} \mathrm{O}, 50 \mathrm{~g}$. of glucose, water to $1 \mathrm{l}$.; the $\mathrm{pH}$ value was adjusted to 6.5. Qualitative trials showed that although in these media all nineteen organisms produced pyruvic acid and ethanol from glucose, accumulation of ethanol was very low in cultures of the majority of the strains of $C$. mycoderma (L series). The latter, except in strains L4 and L6, had very weak fermentative capacities. Oxidative ability in the $\mathrm{L}$ series was fairly well developed, gluconic, lactic and acetic acids being detected as metabolites. In contrast to $C$. mycoderma the strains of the other species of Candida, particularly those of $C$. krusei, were more strongly fermentative and they also exhibited oxidative activities which varied in degree according to the strain, but such oxidative powers were not compared quantitatively with those shown by the strains of $C$. mycoderma. 